\title{
TEMPO E ESPAÇO PARA A BRINCADEIRA DE PAPÉIS SOCIAIS NA EDUCAÇÃO INFANTIL: DOCUMENTOS OFICIAIS E PRÁTICAS PEDAGÓGICAS
}

\author{
Kethelen Rossini ${ }^{1}$ \\ https://orcid.org/0000-0002-1827-4574 \\ Luana Haruka Kawagoe ${ }^{2}$ \\ https://orcid.org/0000-0002-0177-3932 \\ Cassiana Magalhães ${ }^{3}$ \\ (1) https://orcid.org/0000-0002-6609-691X
}

Resumo: O presente artigo objetivou verificar as orientações presentes nos documentos oficiais a respeito da brincadeira de papéis sociais e articulá-las com as implicações na prática pedagógica voltada para as crianças de 3 a 5 anos. Apresenta-se inicialmente uma breve análise dos documentos oficiais da Educação Infantil. A questão norteadora do estudo foi: Qual o tempo e espaço destinado à brincadeira de papéis sociais no contexto da Educação Infantil? Como metodologia utilizou-se a coleta de dados por meio de questionários, além da pesquisa documental, tendo como material os documentos orientadores para a Educação Infantil. Os resultados evidenciaram fragilidades quanto às orientações práticas em relação às brincadeiras de papéis sociais presentes nos documentos oficiais, bem como, a necessidade de estudo e aprofundamento teórico por parte dos professores.

Palavras-chave: educação infantil; documentos oficiais; processo de ensinoaprendizagem; teoria histórico-cultural.

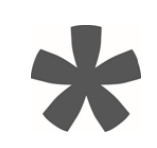

${ }^{1}$ Graduanda em Pedagogia na Universidade Estadual de Londrina. E-mail: kethelenrossini@gmail.com

${ }^{2}$ Graduanda em Pedagogia na Universidade Estadual de Londrina. E-mail: luana.haruka.kawagoe@uel.br

3 Pós-doutora em Educação pela Universidade de Évora - Portugal (2017). Doutora em Educação pela Universidade Estadual Paulista - UNESP (2014). Mestre em Educação pela Universidade Estadual de Londrina - UEL (2007) e Especialista em Educação Infantil pela mesma Universidade (2005). Psicopedagoga Institucional pela Universidade Norte do Paraná - UNOPAR e Pedagoga pela Universidade Tuiuti do Paraná - UTP (2001). Atualmente é professora adjunto D do Departamento de Educação-UEL área de Educação Infantil e professora do Programa de Pós-Graduação na linha 3. E-mail: cassiana@uel.br 


\section{TIME AND SPACE FOR THE ROLE-PLAY GAME IN CHILDHOOD EDUCATION: LEGAL DOCUMENTS AND EDUCATIONAL PRACTICES}

Abstract: The present article aimed to verify the guidelines present in the official documents about the play of social roles and articulate them with the implications in the pedagogical practice for children from 3 to 5 years old. Initially, a brief analysis of the official documents for Early Childhood Education is presented. The guiding question of the study was: What is the time and space allocated for role-playing in the context of Early Childhood Education? The methodology used was data collection through questionnaires, in addition to documentary research, using as material the guiding documents for Early Childhood Education. The results showed weaknesses regarding the practical guidelines for role-playing in the official documents, as well as the need for further study and theoretical deepening by teachers.

Keywords: early childhood education; official documents; teaching-learning process; culturalhistorical theory.

\section{TIEMPO Y ESPACIO PARA LOS JUEGOS DE LOS PAPELES SOCIALES EN LA EDUCACIÓN INFANTIL: DOCUMENTOS OFICIALES Y PRÁCTICAS PEDAGÓGICAS}

Resumen: Este artículo tuvo como objetivo verificar las directrices presentes en los documentos oficiales sobre el juego de roles sociales y articularlas con las implicaciones en la práctica pedagógica para niños de 3 a 5 años. Inicialmente, se presenta un breve análisis de los documentos oficiales de la Educación Infantil. La pregunta que guiaba el estudio era: ¿Cuál es el tiempo y el espacio destinados a los juegos de rol en el contexto de la Educación Infantil? Como metodología se utilizó la recolección de datos a través de cuestionarios, además de la investigación documental, utilizando como material los documentos rectores de la Educación Infantil. Los resultados mostraron debilidades en cuanto a las directrices prácticas en relación con el juego de rol social en los documentos oficiales, así como la necesidad de estudio y profundización teórica por parte de los profesores.

Palabras clave: educación infantil; documentos oficiales; proceso de enseñanza-aprendizaje; teoría histórico-cultural. 


\section{Introdução}

Pressupostos da Teoria Histórico-Cultural indicam que, para que o desenvolvimento psíquico ocorra, há uma atividade que será guia desse processo. Nesse contexto, Leontiev (2001, p. 122) caracteriza a atividade guia (ou dominante) como "[...] aquela em conexão com a qual ocorrem as mais importantes mudanças no desenvolvimento psíquico que preparam o caminho da transição da criança para um novo e mais elevado nível de desenvolvimento", ou seja, o desenvolvimento ocorre a partir dos saltos qualitativos que acontecem nesse período, em decorrência desta atividade, enquanto concomitantemente outras atividades também fazem parte desse processo, a mesma causa maior desenvolvimento das funções psíquicas superiores.

Consideramos importante o conhecimento acerca das concepções dos/as professores/as a respeito da organização do tempo e espaço para que atividade guia da brincadeira de papéis ocorra, já que elas irão embasar suas práticas com as crianças, com isso, podemos pensar que a nossa busca pela compreensão deste tema pelos/as professores/as nos indicará qual lugar a brincadeira de papéis tem na rotina das crianças.

Dessa forma, é possível compreender que a realização da brincadeira de papéis sociais requer planejamento. Partindo da hipótese de que quando o/a professor/a compreende a teoria, e com isso tem condições de realizar um trabalho intencional voltado para o desenvolvimento psíquico infantil, questionou-se: Qual o tempo e espaço destinado a brincadeira de papéis sociais no contexto da Educação Infantil? Tendo como objetivo verificar qual as orientações dos documentos oficiais a respeito da brincadeira de papéis sociais e articulá-las com as implicações na prática pedagógica voltada para as crianças de 3 a 5 anos de idade.

Para a realização deste trabalho, utilizou-se a abordagem de pesquisa qualitativa. A coleta de dados se deu por meio do instrumento questionário, que pode ser definido como "um conjunto de questões, sistematicamente articuladas, que se destinam a levantar informações escritas por parte dos sujeitos pesquisados, com vistas a conhecer a opinião dos mesmos sobre o assunto em estudo" (SEVERINO, 2007, p. 125). A escolha do questionário online se justifica, considerando que nosso público alvo eram os/as professores/as dos municípios da jurisdição do Núcleo Regional de Ensino de Londrina, Paraná (NRE). Esse instrumento em questão é capaz de atingir um número considerável 
de participantes em diferentes áreas geográficas, além de garantir o anonimato daqueles que concordaram em respondê-lo (GIL, 2008).

A escolha dos municípios participantes derivou, de um projeto de extensão, desse modo, o público alvo foram às Instituições de Educação Infantil, públicas, filantrópicas ou privadas dos 19 municípios que compõem a jurisdição do Núcleo Regional de Ensino de Londrina, Paraná. Considerando o momento no qual estávamos vivenciando da pandemia de Covid-19, o questionário foi disponibilizado de forma online, enviados via e-mail, e as respostas, conforme orientações expressas no corpo do questionário deviam considerar o momento anterior à pandemia, ao distanciamento social e as aulas remotas.

Além da análise e interpretação das respostas informadas no questionário, também realizamos a pesquisa documental, tendo como nosso material de pesquisa os documentos oficiais que orientam e norteiam as práticas, currículos e ações na Educação Infantil, nomeadamente, Diretrizes Curriculares Nacionais para a Educação Infantil (BRASIL, 2010); Base Nacional Comum Curricular (BRASIL, 2017); Referencial Curricular do Paraná (PARANÁ, 2018) e nos alicerçamos nos estudos da Teoria Histórico-Cultural para discutir a atividade principal no período da idade em questão, partindo das seguintes categorias (a) apropriação teórica pelo/a professor/a sobre o conceito da Brincadeira de Papéis Sociais; (b) Tempo e Espaço e (c) Planejamento nas instituições de Educação Infantil.

\section{A brincadeira de papéis sociais à luz da Teoria Histórico-Cultural}

A Teoria Histórico-Cultural busca compreender, o processo do desenvolvimento humano, isso inclui os acontecimentos antes mesmo do nascimento, passando pela infância, juventude, fase adulta até por fim chegarmos à velhice. Neste trabalho levaremos em conta o período de desenvolvimento da idade pré-escolar, que se dá aproximadamente entre os 3 e 5 anos de idade da criança.

O conhecimento socialmente construído e as interações sociais são os meios capazes de promover o desenvolvimento humano, conforme afirmam Pasqualini e Eidt (2019, p. 59) “É pela apropriação da cultura historicamente elaborada pela humanidade que os indivíduos desenvolvem sua atividade psíquica complexa e sua personalidade". 
O desenvolvimento das crianças parte do mesmo princípio, ou seja, é a partir das condições sociais, da interação com o ambiente e com o outro que o seu desenvolvimento acontece. Destaca-se que este não é um processo sequencial, e a idade cronológica não é fator determinante, desta forma, este é um processo marcado por saltos qualitativos, fases de crises e de rupturas.

Partindo dos estudos de Abrantes (2012), cada época do desenvolvimento é marcada por períodos, na Primeira Infância temos o período do primeiro ano e da primeira infância, já na época da Infância temos os períodos da idade pré-escolar e da idade escolar. Cada um desses períodos possui consigo uma atividade dominante ou atividade guia. Vale ressaltar a necessidade de uma prática que estimule essas atividades, pois cada período depende do anterior, sendo assim uma atividade é engendrada na outra.

Deste modo, o período do primeiro ano tem como sua atividade dominante a comunicação emocional direta. Durante os primeiros dias de vida o recém-nascido passa grande parte de seu tempo dormindo, esse é o momento em que o bebê está se adaptando à sua nova realidade. É a partir então do segundo e terceiro mês de vida que gradativamente passa a se interessar e interagir com o mundo e as pessoas a sua volta, e a atividade dominante passa então a ser responsável por promover o desenvolvimento do seu psiquismo (CHEROGLU; MAGALHÃES, 2016).

Pasqualini e Eidt (2016, p. 110) apontam que "O primeiro ano da vida de uma criança é marcado pela necessidade objetiva de atenção e cuidados por parte dos adultos". Sendo assim, é possível considerar que durante esse período a relação que o adulto estabelece com o bebê, e as interações que este realiza com o mesmo, são determinantes para o seu desenvolvimento, é a partir dessa relação e das condições organizadas pelos adultos que o desenvolvimento acontece.

Com o declínio da atividade de comunicação emocional direta, tem se início o período da primeira infância, no qual a atividade guia passa a ser a atividade objetal manipulatória, dessa forma, a comunicação com o adulto deixa de ser o centro dos interesses da criança, os objetos, à vontade e capacidade de explorá-los assume essa posição. Esse também é o período marcado tanto pela apropriação da linguagem quanto pela conquista da capacidade de locomoção da criança. (CHAVES; FRANCO, 2016). 
O fim do período da Primeira Infância dá início à época da Infância marcada pelos períodos da Idade Pré-escolar e da Idade Escolar. No período da Idade Pré-Escolar, que ocorre aproximadamente entre o terceiro e o sexto ano de vida da criança, a atividade dominante passa a ser a brincadeira de papéis sociais. De acordo com Lazaretti (2016, p. 129) “Essa nova etapa é resultante das apropriações efetuadas pelo conteúdo da atividade de comunicação emocional direta e da atividade manipulatória objetal, característica do período de 0 a 3 anos". Ou seja, para que uma atividade possa acontecer, as atividades anteriores precisam ser desenvolvidas, como se a nova atividade guia da criança fosse gestada dentro das premissas da atividade anterior.

Cabe ressaltar, que a brincadeira de papéis sociais no período da idade pré-escolar pode ser definida como uma atividade cujo motivo está no próprio processo, por isso, é uma atividade não produtiva na qual a importância se encontra no processo da brincadeira e não no produto final. A criança não entende os motivos que a levam a brincar, logo, a brincadeira além de ser uma atividade não produtiva ocorre sem a criança ter a consciência dos motivos de tal atividade (LEONTIEV, 2001)

Para Elkonin (2009), a brincadeira de papéis sociais é entendida como o ato de representar o homem. Nesse sentido, Lazaretti (2016, p. 131) aponta que "o interesse da criança recai no significado social das ações com os objetos, como são utilizados pelos adultos no interior das relações sociais - fazer o que o adulto faz é o que caracteriza a atividade guia desse período". Dessa forma a representação das atividades e funções sociais dos adultos passa a ser o centro de interesses e do desenvolvimento das crianças.

Ademais, Marcolino, Barros e Mello (2014, p. 98) afirmam que “[...] como não pode ser inserida na sociedade através de uma atividade diretamente útil, ela reconstitui, por meio do jogo, esferas da vida adultas que não lhes estão diretamente acessíveis", ou seja, há uma contradição entre o desejo da criança de fazer parte do mundo adulto, e a impossibilidade do mesmo, visto que ainda não está preparada tanto fisicamente quanto psiquicamente para tal feito, como por exemplo, dirigir um carro.

Refletindo sobre a importância da brincadeira de papéis sociais, temos o ganho de funções psíquicas, em especial o autocontrole da conduta, portanto, quando uma criança assume a representação social de um papel, ela também assume as regras que esse papel 
exige e "uma vez comparadas às ações da vida real, as infrações às regras latentes por uma criança serão objeto de protesto por parte das demais" (SILVANO; PASQUALINI, 2019).

Essa compreensão da brincadeira de papéis e a sua importância para o desenvolvimento do psiquismo da criança nos ajuda a entender a relevância do papel do adulto na organização do planejamento, do tempo e do espaço para que de fato a brincadeira aconteça. Partindo dessas premissas, passaremos à análise das orientações oficiais.

\section{As brincadeiras de papéis sociais sob o olhar dos Documentos Oficiais}

Dentre os documentos oficiais que norteiam e orientam a Educação Infantil a nível nacional e estadual temos as Diretrizes Curriculares Nacionais para a Educação Infantil DCNEI (BRASIL, 2010); A Base Nacional Comum Curricular - BNCC (BRASIL, 2017); O Referencial Curricular do Paraná - RCPR (PARANÁ, 2018). Tendo isso em mente, realizamos a análise destes com o intuito de evidenciar a maneira com a qual a brincadeira de papéis sociais é considerada na Educação Infantil, além disso, buscamos expor quais são as orientações referentes ao trabalho pedagógico para crianças de 3 a 5 anos de idade.

O primeiro documento analisado foi as DCNEI, publicado em 2010 e aprovado pelo Conselho Nacional de Educação, conforme a resolução no 5, de 17 de dezembro de 2009, articulando-se às Diretrizes Curriculares Nacionais da Educação Básica. Tendo como um de seus objetivos "orientar as políticas públicas e a elaboração, planejamento, execução e avaliação de propostas pedagógicas e curriculares de Educação Infantil” (BRASIL, 2010, p. 11).

O documento em si apresenta definições importantes, como a Educação Infantil sendo definida como a primeira etapa da Educação Básica e o reconhecimento da criança como um ser histórico e de direitos. Em relação às orientações do trabalho pedagógico, não há especificidade quanto à faixa etária, porém, no tópico referente à organização de Espaço, Tempo e Materiais há "O reconhecimento das especificidades etárias, das singularidades individuais e coletivas das crianças [...]" (BRASIL, 2010, p. 19), podemos interpretar então que a partir de sua escolha teórica, o/a professor/a fará decisões sobre sua prática pedagógica. 
Ademais, nas DCNEI (BRASIL, 2010) a palavra brincadeira aparece apenas quatro vezes ao longo das 36 páginas, e se limita a expressar a garantia do acesso à brincadeira nas propostas pedagógicas das instituições, como pode ser observado no seguinte trecho "[...] à confiança, ao respeito, à dignidade, à brincadeira, à convivência e à interação com outras crianças" (BRASIL, 2010, p. 18), aos eixos norteadores do currículo (interações e brincadeira), ao processo de avaliação quando: "A observação crítica e criativa das atividades, das brincadeiras e interações das crianças no cotidiano" (BRASIL, 2010, p. 29). Deste modo ela é mencionada poucas vezes, considerando que é uma atividade tão essencial para o desenvolvimento da criança, como discutimos anteriormente.

Dando continuidade ao estudo dos documentos, partimos para a Base Nacional Comum Curricular (BRASIL, 2017) um documento normativo publicado em 22 de dezembro de 2017 por meio da Resolução CNE/CP nํ 2. Nesse documento em questão a palavra brincadeira aparece vinte e seis vezes ao longo do seu segmento da Educação Infantil. Novamente ela é mencionada nos eixos norteadores e também nos objetivos de aprendizagem e desenvolvimento. Desta forma, no decorrer do documento há uma menção ao termo de brincadeira de faz de conta, porém sem nenhum tipo de aprofundamento ou caracterização do termo, observada na seguinte citação, "Por meio das diferentes linguagens, como a música, a dança, o teatro, as brincadeiras de faz de conta, elas se comunicam e se expressam no entrelaçamento entre corpo, emoção e linguagem" (BRASIL, 2017, p. 41).

Em relação às orientações, a BNCC (BRASIL, 2017) nos apresenta os campos de experiência ( $\mathrm{O}$ eu, o outro e o nós; Corpo, gestos e movimentos; Traços, sons, cores e formas; Escuta, fala, pensamento e imaginação; Espaços, tempos, quantidades, relações e transformações) e três grupos por faixa etária, sendo o de crianças de 4 a 5 anos denominado de "crianças pequenas".

No decorrer do documento ainda referente às orientações: comunicar suas ideias, criar com o corpo formas diversificadas de expressão, utilizar sons produzidos por materiais, dentre outros (BRASIL, 2017), e apesar de apresentar meios de se exercer o trabalho docente, o documento não apresenta nenhuma orientação em relação à brincadeira de papéis sociais, no entanto cabe destacar que o "brincar" aparece como um 
direito de aprendizagem e desenvolvimento, o que consideramos como um avanço em relação à educação das crianças.

O próximo documento a se considerar é o Referencial Curricular do Paraná (PARANÁ, 2018). O RCPR é construído a partir da BNCC, pois se entendeu como necessária a construção de um documento específico para cada estado e o seu contexto, tornando-se então um documento de revisão dos currículos de todas as instituições de ensino do Estado do Paraná.

O RCPR (PARANÁ, 2018) apresenta o termo brincadeira quatrocentas e onze vezes em todo o documento e duzentas e setenta e sete vezes nas páginas destinada à Educação Infantil. Nesse documento a brincadeira é considerada como uma das linguagens da infância, como um direito da criança, como meio de manifestações culturais e artísticas e também uma forma de interação e de promover o desenvolvimento, como prática mediadora entre os conhecimentos sistematizados e por fim, tal qual na BNCC, a brincadeira aparece nos objetivos de aprendizagem e desenvolvimento.

De maneira geral o RCPR (PARANÁ, 2018) tornou-se um documento extenso, devido ao seu detalhamento nas diversas formas de propor o trabalho pedagógico, porém um aspecto que nos chama a atenção, se deu pelo fato de haver conteúdos voltados a algo próximo da brincadeira de papéis, como por exemplo: "Participar progressivamente de brincadeiras coletivas assumindo papéis e compartilhando objetos." (PARANÁ, 2018, p. 123); "Identificar características dos personagens das histórias para incrementar cenários e adereços em suas brincadeiras de faz de conta" (PARANÁ, 2018, p. 136); "Participar de brincadeiras de faz de conta, compartilhando propósitos comuns, representando diferentes papéis e convidando outros colegas para participar" (PARANÁ, 2018, p. 149). É possível perceber então, que no documento existe uma maior possibilidade de práticas pedagógicas, além de breves menções dadas ao que podemos entender como brincadeira de papéis sociais.

Partindo desse estudo documental, compreendemos que os documentos oficiais a nível nacional e estadual apresentam pouca ou nenhuma caracterização sobre os conceitos da atividade de brincadeira de papéis sociais como promotora do desenvolvimento das crianças na Educação Infantil entre três e seis anos. A partir desses 
estudos, organizamos uma análise dos questionários, nos quais buscamos compreender como a brincadeira de papéis sociais acontece na Educação Infantil.

\section{A brincadeira de papéis sociais nos municípios da jurisdição do NRE de Londrina - Paraná}

Com o intuito de verificar a forma com a qual a brincadeira de papéis acontece nas instituições de Educação Infantil dos 19 municípios da jurisdição do Núcleo Regional de Ensino de Londrina-PR, um questionário on-line no Google Forms foi elaborado, contando com 8 questões, sendo dessas 5 subjetivas e 3 objetivas.

O questionário foi distribuído para e-mails de participantes das duas últimas jornadas de um evento de Educação Infantil. Ao total aproximadamente 299 e-mails foram enviados e obtivemos 20 respostas anônimas, durante o prazo de 20 dias.

As respostas obtidas contemplaram 6 municípios da jurisdição de Londrina, a saber: 9 professores/as que atuam no município de Londrina, 3 de Sarandi, 2 de Rolândia, 1 de Alvorada do Sul, 1 de Pitangueiras e 1 resposta de um professor que atua em dois municípios ao mesmo tempo, sendo eles Londrina e Cambé. Para além do público alvo recebemos também respostas de outros 2 municípios que não fazem parte da jurisdição, no entanto, estavam participando da jornada de estudo promovida pelo projeto de extensão: 2 de Arapongas e 1 de Telêmaco Borba,

Pudemos perceber que uma maior quantidade de respostas advém do município de Londrina e que os/as professores/as em sua grande maioria atuam em instituições públicas de ensino, os Centros Municipais de Educação Infantil (CMEI).

Após a análise das respostas, notou-se um padrão nas ideias expressas, dessa forma foram organizadas categorias de análise buscando contribuir com a compreensão das mesmas, sendo estas: (a) apropriação teórica pelo/a professor/a sobre o conceito da Brincadeira de Papéis Sociais; (b) Tempo e Espaço e (c) Planejamento nas instituições de Educação Infantil.

Na primeira categoria buscamos compreender o que o/a professor/a entende por brincadeira de papéis sociais, de 20 respostas obtidas, a maioria descreveu como uma 
atividade de reprodução das ações humanas e dos papéis sociais. Dessa forma, para exemplificar elegemos algumas respostas:

A brincadeira de papéis sociais é uma das atividades guias do desenvolvimento humano. Por meio dela, as crianças desempenham os papéis do mundo e isso Ihes possibilita a incorporação da função social do papel desempenhado (PROFESSOR/A DE LONDRINA).

Entendo por brincadeira de papeis sociais a atividade da criança na primeira infância, quando já entende que está brincando e faz na brincadeira coisas que não poderia fazer por ser criança. Exemplo: brincar de médico, professora, etc. (PROFESSOR/A DE SARANDI).

Das respostas restantes, uma pequena parte relacionou a brincadeira de papéis sociais a utilização de brinquedos e a imaginação, como é demonstrado nas seguintes respostas "Eu entendo que seja a maneira como a criança utiliza o brinquedo, usando sua imaginação" (PROFESSOR/A DE ROLÂNDIA); "O brinquedo passa a ser parceiro da criança e ela cria o imaginário e passa a atribuir a este objeto diferentes significados" (PROFESSOR/A DE ROLÂNDIA).

As outras respostas descrevem alguns conceitos sobre a brincadeira e como ela faz parte das vivências das crianças, exemplificada pela resposta "De grande importância para o desenvolvimento da criança e para que ela saiba diferenciar as variadas vivências do meio social" (PROFESSOR/A DE ALVORADA DO SUL).

Como mencionado no decorrer do trabalho, a brincadeira de papéis é a representação do homem, dessa forma de acordo com Lazaretti (2016, p. 132) “[...] aliado a isso, há também procedimentos peculiares, como o de assumir o papel de uma pessoa adulta e de suas funções sociais de trabalho; reproduzir e generalizar ações com os objetos; transferir o significado de um objeto a outro". Compreendemos então que uma parte considerável dos/as professores/as possui conhecimento teórico acerca do tema e compreendem como ele acontece no contexto da Educação Infantil.

Verificamos também que algumas das respostas contavam com exemplos de como a brincadeira de papéis sociais pode ser observada na escola sendo os principais temas as brincadeiras: casinha, bombeiro, policial, cabeleireira e escritório, dentre outros temas.

Em seguida, pensando na segunda categoria de análise, sobre tempo e espaço, questionamos em quais momentos da rotina semanal da criança na escola a brincadeira de papéis sociais acontece. Sendo assim, algumas respostas indicam que os/as 
professores/as buscam planejar o ato de brincar das crianças, ou seja, a brincadeira acontece principalmente, durante atividades planejadas como pode ser observado na seguinte resposta obtida:

No planejamento existem momentos pré estabelecidos desse brincar, entretanto, já aconteceram momentos que partiram de outras situações $e$ o jogo se estabeleceu, não é espontaneismo, mas pela mediação $e$ percepção da professora isso foi possível (PROFESSOR/A DE LONDRINA).

Cabe ressaltar ainda que apesar da maioria das repostas apontar a existência do planejamento desse ato de brincar, a brincadeira aparece também da seguinte forma:

Sempre [...] todos os dias há espaço. Porém, nem todos os dias este brincar é planejado sistematicamente, as vezes acontece em alguns momentos de espera ou transição [...]. Quando é planejado, pode-se, por exemplo iniciar com a apresentação de um papel social [...] de instrumentos necessários para o uso, a distribuição de papéis (PROFESSOR/A DE LONDRINA).

Entretanto algumas respostas fogem completamente desse contexto de planejamento e relatam que a brincadeira acontece baseada na espontaneidade, ou durante o tempo livre da criança entre uma atividade e outra.

Ademais, buscamos saber qual o tempo em que a criança passa diariamente brincando nas escolas, ao elaborarmos a questão tínhamos em mente a brincadeira de papéis sociais, no entanto, ao escrever o enunciado colocamos apenas a palavra "brincadeiras", dessa forma, entendemos que possivelmente ocorreu um equívoco na interpretação da mesma. Sendo assim, a maioria dos/as professores/as que responderam o questionário relataram que as crianças passam em torno de 30 minutos à 1 hora diariamente brincando. Porém, uma parte considerável de professores/as também expôs que a duração da brincadeira das crianças depende do dia, do momento e de seus interesses.

Em relação ao espaço buscamos verificar como o/a professor/a organiza o ambiente, se utilizam recursos prontos, materiais estruturados ou não. Em todas as respostas obtidas os/as professores/as relataram que organizam o espaço e ambiente para a brincadeira com vários recursos, recorrendo a materiais estruturados, como 
fantasias, brinquedos e também a materiais não estruturados, como recicláveis, materiais naturais e cabanas de tecido, como é possível observar na seguinte resposta:

As vezes sou eu que faço a organização desse espaço, algumas vezes com elementos naturais, outras vezes, com reciclados trazidos pelas crianças, outras vezes com os brinquedos da instituição, as vezes fazendo de conta que colchonetes são um rio há uma infinidade de coisas, mas é preciso relatar que algumas vezes são as próprias crianças que organizam esse espaço da brincadeira de papéis sociais instigadas por uma fala, uma história, uma música (PROFESSOR/A DE LONDRINA).

Um/a professor/a também relata utilizar a música e a literatura como meio de organização do espaço de brincadeiras, conforme exemplificado pela seguinte resposta " $A$ sala de aula e, também, os outros ambientes das instituições tem várias possibilidades, assim como apresentar e propiciar literaturas, músicas, movimentos e materiais estruturados ou não ou que favoreçam o brincar/agir/interagir" (PROFESSOR/A DE SARANDI).

O que diferencia em algumas respostas são os relatos onde segundo uma minoria dos/as professores/as poucos são os recursos e materiais disponibilizados pela escola para tal.

No que se refere à esta segunda categoria de análise sobre o tempo e o espaço, Mello (2019, p. 98) entende que:

À medida que vamos apresentando o mundo para as crianças, elas precisam de tempo para experimentar, descobrir, explorar, expressar o que vão descobrindo e aprendendo. Por isso as crianças pequenas na escola de educação infantil precisam de um espaço rico de materiais diversos - que contemplem a cultura inclusive em suas formas mais elaboradas - e de tempo para explorar esses objetos da cultura [...].

Deste modo, entendemos que a organização do tempo e do espaço que a criança tem disponível na Educação Infantil é parte fundante para o seu desenvolvimento em todas as etapas. A diversidade de materiais, rico em qualidade, e a participação do/a professor/a também são condições para que a brincadeira de papéis sociais possa acontecer.

Por último, tendo em mente a categoria de análise sobre o planejamento e a intencionalidade do/a professor/a buscamos saber como o/a mesmo/a se posiciona enquanto a brincadeira de papéis sociais acontece, na maioria das respostas que obtivemos os/as professores/as apontam que buscam criar condições a partir da 
organização do ambiente e dos brinquedos, promovendo situações e hipóteses sobre a brincadeira. Como é demonstrado pela seguinte resposta:

Utilizando todos os meios possíveis, tornando o espaço de aprendizagem voltado para o que se pretende com a brincadeira, oferecendo materiais que enriquecem o repertório dessa criança, partindo do que ela já conhece sobre aquilo, ouvindo-a e dando importância às suas experiências (PROFESSOR/A DE ALVORADA DO SUL).

Ainda sobre a criação de condições uma parte dos/as professores/as busca criar meios a partir de sua interação com o aluno, por meio de problematizações, utilizando recursos como contos, atuando junto com as crianças nas brincadeiras e auxiliando a criança na criação de enredos. Por fim, em uma das respostas o/a professor/a relatou que além de organizar o espaço e os materiais, também proporciona situações de aumento de repertório conforme podemos visualizar na sua resposta:

Ampliando o repertório da criança [...] apresentando funções [...] levando as crianças em trabalhos de campo para que elas compreendam como os adultos exercem suas funções. Oferecendo materiais que podem enriquecer o brincar, organizando espaços, reservando horários para que a brincadeira acontece, delegando papéis para cada 'brincador' (PROFESSOR/A DE LONDRINA).

Questionou-se também sobre a participação do/a professor/a enquanto a brincadeira de papéis sociais acontece, a maioria dos/as professores/as aponta que buscam criar condições para que a sua participação na brincadeira aconteça, outros/as relatam que participam diretamente das brincadeiras, ou então esperam até serem convidados pelas crianças para assim participarem.

Nesse sentido, foi possível verificar que apesar de muitos/as professores/as terem relatado que a brincadeira de papéis acontece diariamente, poucos planejam este momento. Cabe ressaltar a fala na qual o/a professor/a diz que a brincadeira acontece de forma espontânea, porém de acordo com Elkonin (2009, p. 270) "Tudo isso acontece sob direção de adultos e não de maneira espontânea". Sendo assim, existe a necessidade de intervenção do/a professor/a na brincadeira para que ocorra o desenvolvimento da criança.

Mello (2019, p. 97) nos diz que: 
Cabe a nós, professores/as, criar nas crianças o interesse, o desejo de conhecer, manipular, explorar aquilo que apresentamos. Por isso, a forma como apresentamos o mundo para as crianças é parte do nosso compromisso e responsabilidade.

Em relação à intencionalidade podemos nos embasar em Mello (2019), reforçando a importância dos/as professores/as apresentarem às crianças a forma mais elaborada da cultura e criando assim possibilidades de desenvolvimento. Nesse sentido, é necessário que os/as professores/as organizem e apresentem os objetos da cultura, e quanto mais compreenderem o papel da cultura nesse processo de desenvolvimento, mais podem criar situações que favoreçam a brincadeira de papéis sociais. Sendo assim, é fundamental que estejamos em processo contínuo de pesquisa e estudo, buscando uma Educação Infantil de qualidade.

\section{Conclusão}

No decorrer da pesquisa, compreendemos que o trabalho do/a professor/a dessa etapa da Educação Básica, é de extrema importância, pois o/a mesmo/a tem consigo a possibilidade e a responsabilidade de enriquecer o repertório das crianças, além de planejar o momento destinado à brincadeira de papéis sociais, a organização do tempo e espaço, da intencionalidade ao selecionar materiais e o uso de intervenções, durante a brincadeira buscando problematizar e enriquecer a mesma.

Compreendemos os documentos analisados como um avanço considerável na valorização da Educação Infantil como etapa necessária e fundamental da Educação Básica e a sua importância que vai além do contexto educacional, englobando também o contexto social e cultural, além disso, entendemos que não só a brincadeira de papéis sociais, mas a brincadeira em si, são essenciais para o desenvolvimento da criança, entretanto, percebemos que em relação às orientações e contextualização sobre a brincadeira, estas poderiam ser aprimoradas nos documentos em questão.

De maneira geral na análise dos documentos oficiais foi possível observar às fragilidades destes quanto às orientações concernentes à prática pedagógica em relação às brincadeiras de papéis sociais nas escolas de Educação Infantil. Podemos reforçar assim 
a importância do conhecimento teórico para o/a professor/a e que a brincadeira vai muito além da utilização do brinquedo.

Partindo do questionário foi possível notar a existência do conhecimento teórico por parte dos/as professores/as, no qual a maioria dos que se dispuseram a responder, buscaram criar condições e organizar os espaços para que a brincadeira de papéis sociais possa acontecer, respeitando as especificidades de cada criança. Além de contarmos com exemplos nos quais estes apresentam o seu cotidiano escolar. Entretanto, notou-se também algumas imprecisões e inexatidões sobre a teoria e que em alguns casos ainda há muito que o/a professor/a possa fazer e proporcionar às crianças, como por exemplo, criar condições desafiadoras e ampliar os repertórios. O que nos faz refletir sobre a importância e necessidade da formação continuada como ferramenta imprescindível no contexto educacional não só da Educação Infantil, mas de todas as etapas da Educação.

Por fim, entendemos que ao/a professor/a cabe além do lugar de ensino, também o lugar de aprendizagem, o seu papel como educador exige constante busca e apropriação teórica para uma prática pedagógica de qualidade, visto que a teoria está diretamente relacionada à qualidade do ensino. Desta maneira, o/a professor/a ao se apropriar da teoria terá melhores condições de organizar as suas práticas pedagógicas.

\section{Referências}

ABRANTES. Angelo Antonio. Periodização do desenvolvimento psíquico. Bauru: Faculdade de Ciências UNESP, 2012.

BRASIL. Ministério da Educação. Base nacional comum curricular. Brasília: MEC, 2017. Disponível em:

http://basenacionalcomum.mec.gov.br/images/BNCC_EI_EF_110518_versaofinal_site.pdf . Acesso em: 23 jul. 2020.

BRASIL. Ministério da Educação. Diretrizes curriculares nacionais para a educação infantil. Brasília: Ministério da Educação: Secretaria de Educação Básica, 2010. Disponível em: http://www.uac.ufscar.br/domumentos-1/diretrizescurriculares_2012.pdf. Acesso em: 23 jul. 2020. 
CHAVES, Marta; FRANCO, Adriana de Fátima. Primeira infância: educação e cuidados para o desenvolvimento humano. In: MARTINS, L. M.; ABRANTES, A. A.; FACCI, M. G. D.

Periodização histórico-cultural do desenvolvimento psíquico: do nascimento à velhice. Campinas, SP: Autores Associados, 2016. p. 109-126.

CHEROGLU, Simone; MAGALHÃES, Gisele Modé. O primeiro ano de vida: vida uterina, transição pós-natal e atividade de comunicação direta com o adulto. In: MARTINS, L. M.; ABRANTES, A. A.; FACCI, M. G. D. Periodização histórico-cultural do desenvolvimento psíquico: do nascimento à velhice. Campinas, SP: Autores Associados, 2016. p. 93-108.

ELKONIN, Daniil Borisovitch. Psicologia do jogo. São Paulo: Editora WMF Martins Fontes, 2009.

GIL, Antonio Carlos. Métodos e técnicas de pesquisa social. 6. ed. São Paulo: Atlas, 2008.

LAZARETTI, Lucinéia Maria. Idade Pré-Escolar (3-6 anos) e a educação infantil: a brincadeira de papéis sociais e o ensino sistematizado. In: MARTINS, Lucinéia Maria; ABRANTES, A. A.; FACCI, M. G. D. Periodização histórico-cultural do desenvolvimento psíquico: do nascimento à velhice. Campinas, SP: Autores Associados, 2016. p. 129-147.

LEONTIEV, Alexis N. Os princípios psicológicos da brincadeira pré-escolar. In: VIGOTSKII, L. S.; LURIA, A. R.; LEONTIEV, A. N. Linguagem, desenvolvimento e aprendizagem. 9. ed. São Paulo: Ícone, 2001. p. 119-142.

MARCOLINO, Suzana; BARROS, Flávia Cristina Oliveira Murbach de; MELLO, Suely Amaral. A teoria do jogo de Elkonin e a educação infantil. Revista da Associação Brasileira de Psicologia Escolar e Educacional, São Paulo, v. 18, n. 1, p. 97-104, jan./abr. 2014.

MELLO, Suely Amaral. A especificidade do aprender das crianças pequenas e o papel da/o professor/a. In: MAGALHÃES, Cassiana; EIDT, Nadia Mara (org.). Apropriações teóricas e suas implicações na educação infantil. Curitiba: CRV, 2019. p. 93-108.

PARANÁ. [Secretaria de Estado da Educação]. Referencial Curricular do Paraná: princípios, direitos e orientações. [Curitiba: SEED], 2018. Disponível em:

http://www.educadores.diaadia.pr.gov.br/arquivos/File/bncc/2018/referencial_curricular _parana_cee.pdf._Acesso em: 23 jul. 2020.

PASQUALINI, Juliana Campregher; EIDT, Nadia Mara. Periodização do desenvolvimento infantil e ações educativas. In: PASQUALINI, J. C.; TSUHAKO, Y. N. (org.). Proposta pedagógica para a Educação Infantil do Sistema Municipal de Ensino de Bauru/SP. Bauru: Secretaria Municipal de Educação, 2016. p.101-148. Disponível em: http://ead.bauru.sp.gov.br/efront/www/content/lessons/62/Periodiza\%C3\%A7\%C3\%A3o \%20do\%20\%20desenvolvimento\%20infantil\%20e\%20a\%C3\%A7\%C3\%B5es\%20educativas. pdf. Acesso em: 15 jul. 2020. 
PASQUALINI, Juliana Campregher; EIDT, Nadia Mara. A educação como produção da humanidade na criança: relação entre natureza e cultura no desenvolvimento humano e a tarefa do processo educativo. In: MAGALHÃES, Cassiana; EIDT, Nadia Mara (org.). Apropriações teóricas e suas implicações na educação infantil. Curitiba: CRV, 2019. p. 5980.

SEVERINO, Antônio Joaquim. Metodologia do trabalho científico. 23. ed. São Paulo: Cortez, 2007.

SILVANO, F. O. B.; PASQUALINI, J. C. Brincadeira protagonizada como atividade-guia do desenvolvimento da criança pré-escolar: possibilidades didáticas. In: CONGRESSO BRASILEIRO DE EDUCAÇÃO, 7., 2019, Bauru. Anais [...]. Bauru: Unesp, 2019. Disponível em: https://cbe-unesp.com.br/anais/index.php?t=TC2019032908349. Acesso em: 8 ago. 2020.

Recebido em: 24 maio 2021

Aceite em: 31 maio 2021 